\title{
Student satisfaction with the campus bus services at UiTM Shah Alam, Malaysia
}

\begin{abstract}
Campus traffic congestion is a common occurrence because of the factorial increase in enrolment every year. Universities in the Klang Valley, Selangor, Malaysia have to adjust to the situation to appease the stakeholders, in particular the students. With affluent times, many students have their own private vehicle which they drive or ride to school. However, most public universities bar students' vehicles from campus if they were given on-campus housing and on-campus transport is available. In the case of Universiti Teknologi MARA, due to the limited number of dormitories, many students rent out. Consequently, they drive their own vehicles to class or for lesser-affluent ones, the buses and taxis are the popular choice to commute. Thus, the influx of these vehicles is the main cause of traffic congestion. This issue continues to be debatable between the university administrators, the staff and the students. Also, the limited number of parking spaces aggravates the situation, hence, the need to plan for an efficient and effective bus system - the campus hybrid transportation system. In doing so, it is important to get the bus passenger's feedbacks on the current transport services provided. In this case, the units of analysis are the students which form the majority of the bus passengers. Thus, this paper reports the pilot survey on student satisfaction with the campus bus service at the main campus. Through a cross-sectional design, 78 completed responses were analyzed where $28.2 \%$ indicated dissatisfaction with the current bus service. Furthermore, the comments from the respondents provided further evidence that the transportation system on campus has to be reformed. The paper concludes with suggestions for a hybrid transportation system planning, implementation and policy that would guide the success of the project for all stakeholders.
\end{abstract}

